\title{
VIVENDO NO LIMITE! QUAL A FAIXA ÓTIMA DE SOBREVIVÊNCIA DE ISÓPODOS TERRESTRES (ISOPODA, ONISCIDEA) NA PRESENÇA DO ÓLEO ESSENCIAL DE Eucalyptus saligna SM (MYRTACEAE)?
}

\author{
Silveira, L.H.R. ${ }^{1}$; Kenne, D.C. ${ }^{1,2}$ \& Soares, G.L.G. ${ }^{1}$ \\ ${ }^{1}$ Universidade Federal do Rio Grande do Sul (UFRGS), Campus do Vale. Laboratório de Ecologia Química e Quimiotaxonomia. \\ ${ }^{2}$ Universidade Federal do Rio Grande do Sul (UFRGS), Campus do Vale. Laboratório de Carcinologia. \\ *Autor correspondente: luis.ruiz@ufgrs.br
}

\begin{abstract}
Óleos essenciais são misturas de substâncias voláteis vegetais constituídos em grande parte por terpenoides. São originários do metabolismo secundário das plantas e podem atuar contra o ataque de invertebrados fitófagos. Em plantios de Eucalyptus saligna foi observada a presença de tatuzinhos-de-jardim. Porém, sabe-se que as folhas de eucalipto produzem óleos essenciais ricos em monoterpenos tóxicos, têm baixo valor nutricional para os oniscídeos, além de serem esclerificadas, o que pode provocar o desgaste de peças bucais. Visto isso, o presente trabalho buscou identificar uma faixa ótima de sobrevivência dos isópodos terrestres na presença de diferentes quantidades do óleo essencial de E. saligna. Em placas de Petri foram alocados um ou 10 tatuzinhos-de-jardim da espécie Atlantoscia floridana (Van Name, 1940) para testar se a agregação dos animais influenciaria sua sobrevivência. Todas as placas possuíam esferas de algodão embebidas em água destilada para manutenção da umidade local. Na parte interna das tampas das placas foram colocadas esferas de algodão, no qual foi administrado $2 \mu \mathrm{l}$ ou $4 \mu \mathrm{l}$ do óleo essencial de $E$. saligna, ou ainda $\mathrm{H}_{2} \mathrm{O}$ destilada (controle). Em todas as placas haviam discos de Machaerium stipitatum (DC.) Vogel (FABACEAE) de $18 \mathrm{~mm}$ proporcional à quantidade de animais como fonte alimentar. Foram realizadas dez réplicas para cada quantidade de óleo nas placas com um indivíduo, e cinco réplicas para as placas com 10 indivíduos. O experimento durou 15 dias. Os dados foram analisados através de curvas de sobrevivência de Kaplan-meier, seguido do teste de Log-rank (Mantel-Cox) no programa SPSS (PASW Statistcs 18). Em relação às quantidades de óleo essencial, houve diferença significativa para a quantidade de $2 \mu$ l (Log Rank $\chi^{2}=33.49$, $p<0.0001$ ). Quanto à densidade de animais, foi evidenciada maior sobrevivência nos tratamentos com 10 indivíduos (Log Rank $\chi^{2}=13.06, p<0.0001$ ). Com base nos resultados obtidos, um novo ensaio está sendo realizado com a espécie de oniscídeo Armadillidium vulgare Latreille, 1804, com oito animais em todas as placas, devido ao efeito positivo do hábito gregário. As quantidades de óleo essencial se mantêm as mesmas. CNPq.
\end{abstract}

Palavras-Chave: óleo essencial, Eucalyptus saligna, Atlantoscia floridana, Oniscidea, sobrevivência. 